OPEN ACCESS

Edited by:

Marco Marigliano,

Integrated University Hospital

Verona, Italy

Reviewed by:

Adriana Franzese,

University of Naples Federico II, Italy

Elena Fornari,

Integrated University Hospital

Verona, Italy

*Correspondence:

M. Loredana Marcovecchio mlm45@medschl.cam.ac.uk

Specialty section

This article was submitted to

Pediatric Endocrinology,

a section of the journal

Frontiers in Pediatrics

Received: 16 April 2021

Accepted: 17 May 2021

Published: 09 June 2021

Citation:

Chiesa ST and Marcovecchio ML (2021) Preventing Cardiovascular Complications in Type 1 Diabetes: The

Need for a Lifetime Approach

Front. Pediatr. 9:696499.

doi: 10.3389/fped.2021.696499

\section{Preventing Cardiovascular Complications in Type 1 Diabetes: The Need for a Lifetime Approach}

\author{
Scott T. Chiesa ${ }^{1}$ and M. Loredana Marcovecchio ${ }^{2 *}$ \\ ${ }^{1}$ Institute of Cardiovascular Science, University College London, London, United Kingdom, ${ }^{2}$ Department of Paediatrics, \\ University of Cambridge, Cambridge, United Kingdom
}

Cardiovascular disease (CVD) remains the main cause of morbidity and mortality in individuals with type 1 diabetes (T1D). Adolescence appears to be a critical time for the development of early subclinical manifestations of CVD, with these changes likely driven by a deterioration in glycemic control during the progression through puberty, combined with the emergence of numerous other traditional cardiometabolic risk factors (e.g., hypertension, dyslipidemia, smoking, alcohol use, obesity, etc.) which emerge at this age. Although hemoglobin $\mathrm{A} 1 \mathrm{C}$ has long been the primary focus of screening and treatment strategies, glycemic control remains poor in youth with T1D. Furthermore, screening for cardiovascular risk factors - which are often elevated in youth with T1D-is suboptimal, and use of pharmacological interventions for hypertension and dyslipidemia remains low. As such, there is a clear need not only for better screening strategies for CVD risk factors in youth, but also early interventions to reduce these, if future CVD events have to be prevented. Accumulating evidence has recently suggested that early increases in urinary albumin excretion, even within the normal range, may identify adolescents with T1D who are at an increased risk of complications, and results from pharmacological intervention with statins and ACE inhibitors in these individuals have been encouraging. These data join a growing evidence highlighting the need for a whole-life approach to prevention starting from childhood if efforts to improve CVD outcomes and related mortality in T1D are to be maintained.

Keywords: type 1 diabetes, cardiovascular, complications, adolescence, risk factors

\section{INTRODUCTION}

Type 1 diabetes (T1D) is a key public health concern, because of the growing incidence and the increased morbidity and mortality associated with this chronic condition $(1,2)$. Recent estimates from the International Diabetes Federation indicate that worldwide there are over 1 million individuals younger than 19 years living with T1D, with around 100,000 new cases every year in this age group (3). Concern has been raised about the increasing incidence of T1D particularly in very young children (2), as this can lead to higher rates of long-term complications such as retinal and kidney disease, neuropathy, and cardiovascular disease (CVD) - all of which have a negative impact on the prognosis of young people (4).

Although over the last decades there have been key advances in diabetes management, T1D remains a major cause of morbidity, reduced quality of life and loss of productivity (5). In addition, 
premature mortality in individuals with T1D still exceeds that of the background population by $2-4$ fold (6-8). This burden is largely due to vascular complications, with CVD being the leading cause of mortality $(9,10)$. While significant improvements in the clinical management of T1D have made impressive inroads into these troubling figures in recent decades, ever-increasing population levels of obesity and its accompanying metabolic derangements mean that a failure to adequately address more "traditional" CVD risk factors may stall future progress (11).

The purpose of this review is to offer an update on cardiovascular risk in youth with T1D with a focus on (1) nonglycemic risk factors for CVD; (2) new markers/measures for the early detection of CVD, (3) new intervention strategies. Relevant research studies, primarily published in the last 10 years, and including pediatric populations, are reviewed.

\section{THE BURDEN ASSOCIATED WITH CVD IN T1D}

Premature atherosclerosis is the main cause of excess mortality in individuals with T1D, with a standardized mortality attributable to CVD of 5.7 for men and 11.3 for women (12). Individuals with T1D experience an earlier onset of cardiovascular events and a higher related mortality compared to their peers without diabetes, and women with $\mathrm{T} 1 \mathrm{D}$ are at higher risk than men $(13,14)$.

The incidence of major coronary artery disease events in young adults (aged 28-38 years) with T1D is around $1 \%$ per year and increases over 3\% per year after age 55 years (4). Evidence of premature atherosclerosis may be evident in as many as $50-70 \%$ individuals with T1D by the age of 45 years, and a significant proportion of young people will have clinical cardiovascular risk factors already detectable by the age of 12-19 years (15).

Great strides been made in recent decades to lower mortality in people with T1D (16), with most of this success attributed to improvements in glycemic control due to better insulin regimens along with the introduction of continuous subcutaneous insulin infusion and continuous glucose monitoring, and more recently hybrid closed loop systems (17). Nevertheless, individuals with T1D still experience significant excess morbidity and mortality, as evidenced by a recent Danish study assessing mortality in children and young adults (age 1-39 years) in which a 7-fold increase in allcause mortality and 11-fold increase in cardiovascular mortality was observed compared to age-matched individuals without diabetes (18).

\section{ADOLESCENCE IS A CRITICAL TIME FOR THE ONSET OF CARDIOVASCULAR DISEASE}

Although the clinical manifestations of CVD are almost exclusively observed in later life, their incidence represents the end-result of decades-long subclinical disease process which is driven in large part by potentially modifiable lifestyle behaviors and risk factors (19) (Figure 1). In individuals with childhoodonset T1D, adolescence appears to be a particularly critical period for this process (20). This has been starkly illustrated by findings from the Swedish National Diabetes Register, in which T1D onset before the age of 10 years was associated with a loss of life expectancy of 17.7 years in women and 14.2 years in men, as compared with 10.1 and 9.4 years respectively in those with T1D onset at age $26-30$ years (7). Furthermore, individuals with childhood-onset T1D were found to have a 30-times higher CVD risk than the general population (7). Further data from the US National Health Interview Survey support this, indicating that whereas deaths related to vascular complications declined over time in adults, they remained almost unchanged in young people with T1D aged 22-44 years (21). This higher risk of CVD in people with an early onset of T1D is likely related to a longer duration of risk factor exposure in individuals diagnosed in childhood, alongside a potentially more aggressive disease pathogenesis (22).

While suboptimal glycemic control likely plays a major role in this elevated risk, it is now well-established that early and sustained exposure to "traditional" CVD risk factors such as high BMI, blood pressure and cholesterol, physical inactivity, poor diet, and smoking (amongst others) likely accelerate the atherosclerotic disease process and further contribute to future CVD risk $(19,23)$ (Figure 1). These adverse risk factors frequently track across the lifespan, with individuals who are exposed to a high-risk factor burden already during adolescence more likely to carry this increased burden into later-life (24). This early and cumulative exposure to multiple risk factors throughout adolescence may therefore be particularly damaging in individuals with childhoodonset T1D, especially as it occurs alongside progressively worsening HbA1c levels (25). In support of this, multiple studies in individuals with T1D have demonstrated that it is during this period of life that the first signs of vascular damage often appear (26). These early vascular complications may be particularly aggressive in those with poor glycemic control (27), and have been shown to increase even further in those additionally exposed to other traditional risk factors (28).

The most common method for assessing these early subclinical manifestations are through the use of surrogate markers such as increased arterial wall thickness (carotid intimamedia thickness, cIMT), accelerated arterial stiffening (pulse wave velocity, PWV), or endothelial dysfunction (flow mediated dilation, FMD) $(15,29)$. A recent systematic review and metaanalysis including 23 studies on cIMT and carotid-femoral PWV showed higher cIMT and PVW in youth with T1D than matched controls (30).

With recent evidence demonstrating a remarkable ability for even modest reductions in risk factors to substantially reduce cardiovascular events when sustained across the life-course (31), it is clear that efforts to mitigate risk factor exposure should start as early as possible and continue during the transition through adulthood, if maximal lifetime benefits are to be achieved. 


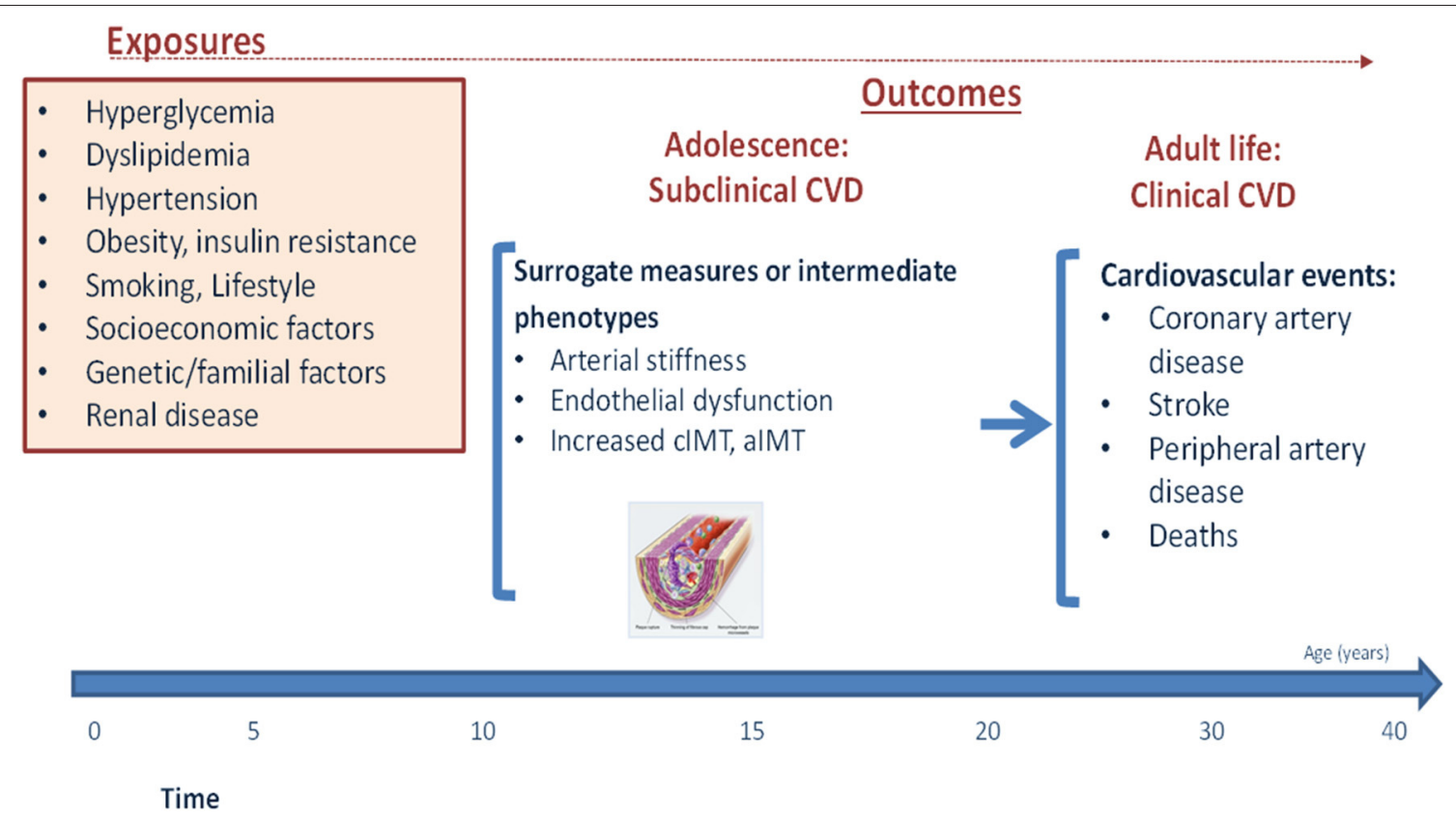

FIGURE 1 | Natural history of cardiovascular disease in youth with Type 1 diabetes.

\section{NON-GLYCEMIC CVD RISK FACTORS IN YOUTH WITH T1D: A BURGEONING CONCERN}

Poor glycemic control is the primary modifiable risk factor for CVD in T1D, as clearly highlighted by the results of the DCCT/EDIC studies and other more recent studies (32). However, other traditional cardiometabolic risk factors such as obesity, hypertension, and dyslipidemia; lifestyle factors such as smoking and physical inactivity, and comorbidities such as microalbuminuria, hyperfiltration/delcline in renal function can all independently and additively contribute to overall CVD risk (32).

\section{Cardiometabolic Risk Factors}

The increased prevalence of obesity in the past three decades has particularly alarmed the global health community, with up to $60 \%$ of the world's population now projected to become overweight or obese within 10 years if current trends continue (33). Worryingly, the most rapid increases in obesity during this time have been in the young-the vast majority of whom will go onto become obese adults (34). Although individuals with T1D were traditionally considered to be a relatively lean population, recent evidence has shown that obesity rates in this group are now similar or possibly even higher than in the general population, with an alarmingly high prevalence particularly in children and adolescents (35). Indeed, recent data based on large registries from the US, Australia and Europe have confirmed that overweight and obesity are common among youth with T1D at rates of $9-20 \%$ (36). Given the known causal relationship between obesity, its accompanying sequelae of cardiometabolic derangements, and CVD; these data suggest that recent improvements in CVD morbidity/mortality, which have been largely attributed to improved glycemic control, could now be at risk of stalling or even being reversed due to the emergence of these additional emerging risk factors (11).

Unfortunately, evidence suggests that youth with T1D are disproportionately affected by these risk factors when compared to their healthy peers, and the presence of many of these factors are therefore already common among youth with T1D. For example, recent studies have suggested that up to $60 \%$ of children may show evidence of cardiometabolic risk factors around the time of diagnosis $(37,38)$, and around $86 \%$ of individuals may have one and $14-45 \%$ more than two cardiovascular risk factors by the time they reach adolescence (15). Similar findings have been reported from the SEARCH study, in which 7\% of T1D youth had two or more CVD risk factors and $1.7 \%$ had three or more. In these individuals, $26 \%$ participants were overweight, $14 \%$ obese, $13 \%$ hypertensive, and $29 \%$ dyslipidemic (32). In longitudinal follow-up, while the number of these risk factors did not significantly change over the 10 -year study period [20022012], a strong relationship was found between BMI and CVD risk factors, and a clustering of CVD risk factors was associated with high rates of multiple vascular complications (39). Likewise, in a recent large Italian study, assessing 2021 young people with T1D aged 2-18 years, CVD risk factors were confirmed to be common, with $32.5 \%$ showing one CVD risk factor and $6.7 \%$ two risk factors (40).

\section{Lifestyle Risk Factors}

In addition to cardiometabolic derangements, lifestyle factors such as smoking, alcohol, sedentary behavior, and stress can 
also contribute to CVD (15). Among teenagers with T1D, $10 \%$ reported alcohol consumption, $10 \%$ were smokers and $6 \%$ reported both alcohol and cigarette use (41). Both smoking and alcohol in youth are associated with suboptimal glycemic control, alongside a higher prevalence of other CVD risk factors (41).

\section{Emerging Risk Factors}

$\mathrm{DKD}$ is an independent risk factor for cardiovascular morbidity and mortality $(42,43)$. Albuminuria, the hallmark of DKD, is associated with two to four times greater risk for CVD and death (44), and there is strong evidence that urinary albumin excretion is a continuous CVD risk factor (45). Longitudinal studies of adolescents with T1D recruited to the Oxford Regional Prospective Study, Nephropathy Family Study and the Adolescent Type 1 Diabetes cardio-renal Intervention Trial (AdDIT), have highlighted these observations (26). In these young cohorts, increases in the urinary ACR may occur as early as 1 year from T1D diagnosis in those who progress to microalbuminuria or macroalbuminuria (46). Furthermore, these modest increases in albumin excretion are not only linked to early risk for the development of microalbuminuria (46) but also to CVD risk factors such as carotid intima-media thickness, flow-mediated dilation, C-reactive protein, and over time changes in blood pressure $(47,48)$. Thus, urinary ACR is an important CVD risk marker in addition to traditional predictive risk factors in T1D. In addition, decline in glomerular filtration rates, which can occur already in youth with $\mathrm{T} 1 \mathrm{D}$, is an additional risk factor for CVD (49).

\section{HOW BEST TO TACKLE CVD RISK FACTORS DURING ADOLESCENCE?}

Collectively, the above findings have led to guidelines from organizations such as the International Society for Pediatric and Adolescent Diabetes and American Diabetes Association to recommend screening for CVD risk factors (primarily dyslipidemia, high blood pressure, obesity, and smoking) starting from the age of 10-11 years (50). Despite these recommendations, however, strategies on how to appropriately address these once identified remain suboptimal.

During adolescence, the primary focus of management of vascular complications risk is to improve glycemic control by intensifying insulin therapy (50). However, despite advances in insulin treatment, over $75 \%$ adolescents do not reach recommended targets for $\mathrm{HbA1c}(25)$.

In addition to issues with glycemic control, many adolescents also do not meet targets for blood pressure, cholesterol or BMI (15), potentially compounding the excess risk experienced in T1D that arises from high blood glucose levels. Guidelines recommend lifestyle interventions as first steps to control these risk factors before implementing drug interventions (50), despite a lack of strong evidence for their effectiveness. Weight management in youth with T1D presents its own challenges, with fear of hypoglycemia, difficult management of glycemic control during exercise and inadequate knowledge around exercise management representing potential barriers to increased levels of physical activity (51). Furthermore, while adherence to dietary guidelines is associated with improved glycemia, youth struggle to meet strict dietary recommendations-particularly during the critical transition through adolescence when newfound freedoms from parental oversight and other social pressures often have negative effects on diet or other health behaviors (52).

Despite these difficulties, however, robust evidence exists to suggest that the adoption of several relatively simple lifestyle changes in the early years of life are likely to significantly reduce risk of CVD in later years. In the general population, evidence from the CARDIA study has shown the remarkable effect that good health behaviors in adolescence/young adulthood have on cardiovascular risk in later life, with adolescents with 5 or more healthy lifestyle behaviors (as defined by the American Heart Association and comprising blood pressure, total cholesterol, glucose/HbA1c, BMI, physical activity, diet, smoking) over 20 times more likely to have a favorable cardiovascular health profile in 20 year-follow-up compared to those with 0 healthy behaviors (53). These findings have recently been replicated in individuals with T1D for the first time, suggesting that these metrics represent straightforward goals for health promotion that may reduce CVD risk in the T1D population (54). Together, these findings highlight the need for more focus on education and training on exercise and lifestyle change in diabetes to enable the implementation of early intervention programmes to tackle poor cardiovascular health from a young age.

\section{DRUG INTERVENTIONS: WHERE ARE WE?}

Similar to lifestyle changes, recent studies have highlighted a 'therapeutic inertia' related to treatment of CVD risk factors such as dyslipidemia and hypertension in youth with T1D, with low rates of use of antihypertensive or lipid-lowering medications even where there is an indication for their use $(55,56)$. Data from T1D registries from the United States and Germany/Austria have confirmed that most young patients are inadequately treated for hypertension and dyslipidaemia (57). Few young adults aged $<26$ years receive antihypertensive (3-5\%) and lipid-lowering (1-3\%) medications, highlighting the need for improved diabetes and cardiovascular risk management strategies in T1D.

Survey data suggest that clinicians endorse lifestyle recommendations for initial management of dyslipidemia and hypertension in $83-99 \%$ of cases, although only $6-17 \%$ of them believe that these are effective. In contrast, medications are rarely prescribed (58), partly due to limited data and guideline recommendations for the use of common drugs such as statins and ACE inhibitors use in adolescents with T1D.

\section{Statins and ACE-Inhibitors in Adolescents With T1D}

AdDIT was the first large randomized clinical trial evaluating the use of ACE inhibitors and statins during adolescence to protect against T1D vascular complications (59). The trial showed that statins can reduce exposure to high lipid levels and ACE-inhibitors can reduce new cases of microalbuminuria; changes that could potentially lead to protection against future 
complications (59). In addition, a recent analysis of a subgroup of the trial population showed that ACE inhibitors improved endothelial function (assessed by flow mediated dilation) in high-risk adolescents transitioning through puberty, and may therefore offer long-term cardio-renal benefit during this potentially critical time period for the development of CVD (48).

The trial also provided reassuring data on the safety profile of both drugs in this age group (59). Overall adherence during the 2-4 year trial period was $75-80 \%$, although it deteriorated over time, therefore highlighting the need of strategies to reinforce adherence to gain the maximum benefit from these interventions (60).

Participants from the AdDIT study are now entering their $2^{\text {nd }}$ to $3^{\text {rd }}$ decade from T1D diagnosis, a time when more pronounced arterial changes begin to emerge. Current follow-up of the study cohort up to 5 years from the end of the original trial, including detailed cardiovascular phenotyping, will provide invaluable information on the potential impact of cumulative exposure to acquired modifiable risk factors on CVD progression. The study will also determine whether a reduction in these risk factors during adolescence because of statin/ACE-inhibitors therapy results in long-term benefits for CVD health.

\section{Metformin in Youth With T1D}

Metformin is another potential treatment in youth with T1D. Although there is no strong evidence in terms of glycemic control following metformin treatment, its use has been shown to lead to small reductions in total daily insulin dose and BMI in youth with T1D (61). Furthermore, recent studies have shown a beneficial effect on insulin sensitivity and CVD risk profile. In one study, a 3-month intervention with metformin led to greater improvements in insulin sensitivity compared to placebo (62), while a second smaller study on 16 youth with T1D showed that 12-month treatment with metformin improved vascular smooth muscle function (63). In a more recent mechanistic study, 48 youth with T1D (aged 12-21 years) underwent a hyperinsulinemic euglycemic clamp and assessment of MRIderived measures of aortic and carotid vascular health, before and after 3 months of metformin or placebo therapy. Treatment with metformin was associated with improved insulin sensitivity and aortic and carotid wall measures (64). Additional larger studies are required to confirm these findings and provide additional evidence before metformin could be recommended as an adjunct therapy in T1D.

\section{Other Adjunct Medications in Youth With T1D}

Non-insulin therapies, such as sodium-glucose co-transporter 2 (SGLT2) inhibitors, glucagon-like peptide-1 receptor agonist and dipeptidyl peptidase- 4 inhibitors, have been investigated to try to improve glycemic control, as well as for their potential effect in CVD risk factors (65).

A large body of evidence support a positive effect of SGLT2inhibitors on cardiovascular and renal outcomes in adults with diabetes, although data for the pediatric population are lacking (65). While these medications appear promising, the risk for euglycemic diabetic ketoacidosis is still a potential limiting factor to consider before a wide implementation in the pediatric population (65).

\section{MOTIVATIONAL AND PSYCHOLOGICAL INTERVENTIONS}

Data based on semi-structured interviews have clearly shown poor awareness of complications among adolescents as well their reluctance to know about them (66). Even when patients are aware, however, a combination of insufficient support for how to implement lifestyle changes, lack of confidence to follow these changes, and lack of knowledge on other means for controlling blood pressure and lipid levels may all limit uptake of preventative measures (67). More effort is therefore required to not only raise awareness about complications in youth, but also to develop better ways to quantify and communicate this risk to patients and their families. To achieve this, potential barriers limiting adherence to weight management and lifestyle strategies should be identified and addressed (51), and reassurance about medical treatment of dyslipidemia and hypertension should be provided to both young patients and their parents.

Properly addressing physical activity, nutrition, pharmacotherapy, and psychosocial factors while emphasizing weight management may improve CVD risk factors and avoid their persistence during adulthood.

\section{UNANSWERED QUESTIONS AND FUTURE DIRECTIONS}

\section{Early Prediction}

There is still a need for improved ways to identify people at risk at an early stage when pathology may be amenable to interventions.

Early screening for abnormal ACR may provide a valuable tool to identify adolescents at high risk for CVD in clinical practice. Risk stratification using urinary albumin excretion along with other traditional and new risk factors during early adolescence may be critical for the early identification of patients at risk and to guide the implementation of preventive and treatment strategies.

\section{Early Prevention/Better Interventions}

There is an urgent need to identify new targets for interventions to prevent CVD complications, and this can only be achieved through a better understanding of the mechanisms and key players implicated in the development and progression of vascular complications.

While the AdDIT trial has provided evidence that early interventions with ACE-Inhibitors and statins are both safe and effective in reducing exposure to CVD risk factors during adolescence, the impact of these early interventions on longterm cardiovascular outcomes needs to be further explored. For any intervention to provide maximum efficacy, strategies to promote adherence to both existing and new interventions will be required-especially given known issues surrounding adherence levels common during the transition from adolescence to adulthood. In addition, lifestyle interventions need to be more 
widely promoted and made easy to be implemented for youth with T1D.

\section{CONCLUSIONS}

Despite significant improvements in the management of T1D during the past decades, vascular complications remain a major concern. Efforts to improve vascular outcomes and mortality in T1D should be a whole-life approach starting from childhood.

\section{REFERENCES}

1. Dabelea D, Mayer-Davis EJ, Saydah S, Imperatore G, Linder B, Divers J, et al. Prevalence of type 1 and type 2 diabetes among children and adolescents from 2001 to 2009. JAMA. (2014) 311:1778. doi: 10.1001/jama.2014.3201

2. Patterson CC, Harjutsalo V, Rosenbauer J, Neu A, Cinek O, Skrivarhaug $\mathrm{T}$, et al. Trends and cyclical variation in the incidence of childhood type 1 diabetes in 26 European centres in the 25 year period 1989-2013: a multicentre prospective registration study. Diabetologia. (2019) 62:40817. doi: 10.1007/s00125-018-4763-3

3. IDF Diabetes Atlas 9th edition. (2019). Available online at: https://www. diabetesatlas.org/en/ (accessed April 16, 2021).

4. Secrest AM, Becker DJ, Kelsey SF, Laporte RE, Orchard TJ. Causespecific mortality trends in a large population-based cohort with longstanding childhood-onset type 1 diabetes. Diabetes. (2010) 59:321622. doi: $10.2337 / \mathrm{db} 10-0862$

5. Magliano DJ, Martin VJ, Owen AJ, Zomer E, Liew D. The productivity burden of diabetes at a population level. Diabetes Care. (2018) 41:979-84. doi: $10.2337 / \mathrm{dc} 17-2138$

6. Livingstone SJ, Levin D, Looker HC, Lindsay RS, Wild SH, Joss N, et al. Estimated life expectancy in a Scottish cohort with type 1 diabetes, 2008-2010. JAMA. (2015) 313:37-44. doi: 10.1001/jama.2014.16425

7. Rawshani A, Sattar N, Franzén S, Rawshani A, Hattersley AT, Svensson A-M, et al. Excess mortality and cardiovascular disease in young adults with type 1 diabetes in relation to age at onset: a nationwide, register-based cohort study. Lancet. (2018) 392:477-86. doi: 10.1016/S0140-6736(18)31506-X

8. Miller RG, Mahajan HD, Costacou T, Sekikawa A, Anderson SJ, Orchard TJ. A contemporary estimate of total mortality and cardiovascular disease risk in young adults with type 1 diabetes: the pittsburgh epidemiology of diabetes complications study. Diabetes Care. (2016) 39:2296303. doi: $10.2337 / \mathrm{dc} 16-1162$

9. Sharma H, Lencioni M, Narendran P. Cardiovascular disease in type 1 diabetes. Cardiovasc Endocrinol Metab. (2019) 8:2834. doi: 10.1097/XCE.0000000000000167

10. de Ferranti SD, de Boer IH, Fonseca V, Fox CS, Golden SH, Lavie CJ, et al. Type 1 diabetes mellitus and cardiovascular disease: a scientific statement from the American heart association and American diabetes association. Circulation. (2014) 130:1110-30. doi: 10.1161/CIR.0000000000000034

11. Corbin KD, Driscoll KA, Pratley RE, Smith SR, Maahs DM, Mayer-Davis EJ. Obesity in type 1 diabetes: Pathophysiology, clinical impact, and mechanisms. Endocr Rev. (2018) 39:629-63. doi: 10.1210/er.2017-00191

12. Huxley RR, Peters SAE, Mishra GD, Woodward M. Risk of all-cause mortality and vascular events in women versus men with type 1 diabetes: A systematic review and meta-analysis. Lancet Diabetes Endocrinol. (2015) 3:198-206. doi: 10.1016/S2213-8587(14)70248-7

13. Orchard TJ, Costacou T, Kretowski A, Nesto RW. Type 1 diabetes and coronary artery disease. Diabetes Care. (2006) 29:2528-38. doi: 10.2337/dc06-1161

14. Cai X, Li J, Cai W, Chen C, Ma J, Xie Z, et al. Meta-analysis of type 1 diabetes mellitus and risk of cardiovascular disease. J Diabetes Complications. (2021) 35:107833. doi: 10.1016/j.jdiacomp.2020.107833

15. Bjornstad P, Donaghue KC, Maahs DM. Macrovascular disease and risk factors in youth with type 1 diabetes: time to be more attentive to treatment? Lancet Diabetes Endocrinol. (2018) 6:809-20. doi: 10.1016/S2213-8587(18)30035-4
Early investment in the understanding and care of youth with T1D from childhood will have substantial long-term benefits in terms of complications, quality of life, and life expectancy.

\section{AUTHOR CONTRIBUTIONS}

SC and MM reviewed literature and worked together on the manuscript draft and approved final version. Both authors contributed to the article and approved the submitted version.

16. Rawshani A, Rawshani A, Franzén S, Eliasson B, Svensson A-M, Miftaraj M, et al. Mortality and cardiovascular disease in type 1 and type 2 diabetes. $N$ Engl J Med. (2017) 376:1407-18. doi: 10.1056/NEJMoa1608664

17. Tauschmann M, Hovorka R. Technology in the management of type 1 diabetes mellitus-current status and future prospects. Nat Rev Endocrinol. (2018) 14:464-75. doi: 10.1038/s41574-018-0044-y

18. Svane J, Lynge TH, Pedersen-Bjergaard U, Jespersen T, Gislason GH, Risgaard $\mathrm{B}$, et al. Cause-specific mortality in children and young adults with diabetes mellitus: a danish nationwide cohort study. Eur J Prev Cardiol. (2019) 28:15965. doi: 10.1177/2047487319836550

19. Celermajer DS, Ayer JGJ. Childhood risk factors for adult cardiovascular disease and primary prevention in childhood. Heart. (2006) 92:17016. doi: 10.1136/hrt.2005.081760

20. Cho YH, Craig ME, Donaghue KC. Puberty as an accelerator for diabetes complications. Pediatr Diabetes. (2014) 15:18-26. doi: 10.1111/pedi.12112

21. Gregg EW, Cheng YJ, Srinivasan M, Lin J, Geiss LS, Albright AL, et al. Trends in cause-specific mortality among adults with and without diagnosed diabetes in the USA: an epidemiological analysis of linked national survey and vital statistics data. Lancet. (2018) 391:2430-40. doi: 10.1016/S0140-6736(18)30314-3

22. Forbes JM, Fotheringham AK. Vascular complications in diabetes: old messages, new thoughts. Diabetologia. (2017) 60:212938. doi: 10.1007/s00125-017-4360-x

23. Berenson GS, Srinivasan SR, Bao W, Newman WP, Tracy RE, Wattigney WA. Association between multiple cardiovascular risk factors and atherosclerosis in children and young adults. N Engl J Med. (1998) 338:1650-6. doi: 10.1056/NEJM199806043382302

24. Karmali KN, Lloyd-Jones DM. Achieving and maintaining cardiovascular health across the lifespan. Curr Epidemiol Rep. (2014) 1:75-81. doi: 10.1007/s40471-014-0011-7

25. Foster NC, Beck RW, Miller KM, Clements MA, Rickels MR, DiMeglio LA, et al. State of type 1 diabetes management and outcomes from the T1D exchange in 2016-2018. Diabetes Technol Ther. (2019) 21:6672. doi: 10.1089/dia.2018.0384

26. Marcovecchio ML, Dalton RN, Daneman D, Deanfield J, Jones TW, Neil HAW, et al. A new strategy for vascular complications in young people with type 1 diabetes mellitus. Nat Rev Endocrinol. (2019) 15:42935. doi: 10.1038/s41574-019-0198-2

27. Amin R, Widmer B, Prevost AT, Schwarze P, Cooper J, Edge J, et al. Risk of microalbuminuria and progression to macroalbuminuria in a cohort with childhood onset type 1 diabetes: Prospective observational study. BMJ. (2008) 336:697-701. doi: 10.1136/bmj.39478.378241.BE

28. Maahs DM, Daniels SR, de Ferranti SD, Dichek HL, Flynn J, Goldstein BI, et al. Cardiovascular disease risk factors in youth with diabetes mellitus: a scientific statement from the american heart association. Circulation. (2014) 130:1532-58. doi: 10.1161/CIR.0000000000000094

29. Schäfer M, Nadeau KJ, Reusch JEB. Cardiovascular disease in young People with Type 1 Diabetes: Search for Cardiovascular Biomarkers. J Diabetes Complications. (2020) 34:107651. doi: 10.1016/j.jdiacomp.2020. 107651

30. Giannopoulou EZ, Doundoulakis I, Antza C, Christoforidis A, Haidich A-B, Kotsis V, et al. Subclinical arterial damage in children and adolescents with type 1 diabetes: a systematic review and meta-analysis. Pediatr Diabetes. (2019) 20:668-77. doi: 10.1111/pedi.12874 
31. Ference BA, Bhatt DL, Catapano AL, Packard CJ, Graham I, Kaptoge $\mathrm{S}$, et al. Association of genetic variants related to combined exposure to lower low-density lipoproteins and lower systolic blood pressure with lifetime risk of cardiovascular disease. JAMA. (2019) 322:138191. doi: 10.1001/jama.2019.14120

32. Urbina EM, Isom S, Bell RA, Bowlby DA, D’Agostino R, Daniels SR, et al. Burden of cardiovascular risk factors over time and arterial stiffness in youth with type 1 diabetes mellitus: the SEARCH for diabetes in youth study. J Am Heart Assoc. (2019) 8:e010150. doi: 10.1161/JAHA.118.010150

33. Kelly T, Yang W, Chen CS, Reynolds K, He J. Global burden of obesity in 2005 and projections to 2030. Int J Obes. (2008) 32:14317. doi: $10.1038 /$ ijo.2008.102

34. Ward ZJ, Long MW, Resch SC, Giles CM, Cradock AL, Gortmaker SL. Simulation of growth trajectories of childhood obesity into adulthood. $\mathrm{N} \mathrm{Engl}$ J Med. (2017) 377:2145-53. doi: 10.1056/NEJMoa1703860

35. Liu LL, Lawrence JM, Davis C, Liese AD, Pettitt DJ, Pihoker C, et al. Prevalence of overweight and obesity in youth with diabetes in USA: The SEARCH for diabetes in youth study. Pediatr Diabetes. (2010) 11:411. doi: 10.1111/j.1399-5448.2009.00519.x

36. Phelan H, Foster NC, Schwandt A, Couper JJ, Willi S, Kroschwald P, et al. Longitudinal trajectories of BMI z-score: an international comparison of 11,513 Australian, American and German/Austrian/Luxembourgian youth with type 1 diabetes. Pediatr Obes. (2020) 15:e12582. doi: 10.1111/ijpo.12582

37. Jones S, Khanolkar AR, Gevers E, Stephenson T, Amin R. Cardiovascular risk factors from diagnosis in children with type 1 diabetes mellitus: a longitudinal cohort study. BMJ Open Diabetes Res Care. (2019) 7:e000625. doi: 10.1136/bmjdrc-2018-000625

38. Kim G, Divers J, Fino NF, Dabelea D, Lawrence JM, Reynolds K, et al. Trends in Prevalence of Cardiovascular Risk Factors from 2002-2012 among Youth Early in the Course of Type 1 and Type 2 Diabetes. The SEARCH for Diabetes in Youth Study. Pediatr Diabetes. (2019) 20:693-701. doi: 10.1111/pedi.12846

39. Sauder KA, Stafford JM, Mayer-Davis EJ, Jensen ET, Saydah S, Mottl A, et al. Co-occurrence of early diabetes-related complications in adolescents and young adults with type 1 diabetes: an observational cohort study. Lancet Child Adolesc Heal. (2019) 3:35-43. doi: 10.1016/S2352-4642(18)30309-2

40. Fornari E, Piona C, Rabbone I, Cardella F, Mozzillo E, Predieri B, et al. Cardiovascular risk factors in children and adolescents with type 1 diabetes in Italy: a multicentric observational study. Pediatr Diabetes. (2020) 21:154655. doi: $10.1111 /$ pedi.13123

41. Valerio G, Mozzillo E, Zito E, De Nitto E, Maltoni G, Marigliano $\mathrm{M}$, et al. Alcohol consumption or cigarette smoking and cardiovascular disease risk in youth with type 1 diabetes. Acta Diabetol. (2019) 56:131521. doi: 10.1007/s00592-019-01415-5

42. Groop P-H, Thomas MC, Moran JL, Wadèn J, Thorn LM, Mäkinen $\mathrm{V}-\mathrm{P}$, et al. The presence and severity of chronic kidney disease predicts all-cause mortality in type 1 diabetes. Diabetes. (2009) 58:1651-8. doi: 10.2337/db08-1543

43. Miller RG, Costacou T, Orchard TJ. Risk factor modeling for cardiovascular disease in type 1 diabetes in the pittsburgh epidemiology of diabetes complications (EDC) study: A comparison with the diabetes control and complications trial/epidemiology of diabetes interventions and complications study (DCCT/EDIC). Diabetes. (2019) 68:409-19. doi: 10.2337/db18-0515

44. Rawshani A, Rawshani A, Sattar N, Franzén S, Mcguire DK, Eliasson B, et al. Relative prognostic importance and optimal levels of risk factors for mortality and cardiovascular outcomes in type 1 diabetes mellitus. Circulation. (2019). 139:1900-12. doi: 10.1161/CIRCULATIONAHA.118.037454

45. Matsushita K, Coresh J, Sang Y, Chalmers J, Fox C, Guallar E, et al. Estimated glomerular filtration rate and albuminuria for prediction of cardiovascular outcomes: a collaborative meta-analysis of individual participant data. Lancet Diabetes Endocrinol. (2015) 3:514-25. doi: 10.1016/S2213-8587(15)00040-6

46. Dunger DB, Schwarze CP, Cooper JD, Widmer B, Neil HAW, Shield J, et al. Can we identify adolescents at high risk for nephropathy before the development of microalbuminuria? Diabet Med. (2007) 24:1316. doi: 10.1111/j.1464-5491.2006.02047.x

47. Marcovecchio ML, Chiesa ST, Armitage J, Daneman D, Donaghue KC, Jones TW, et al. Renal and cardiovascular risk according to tertiles of urinary albumin-to-creatinine ratio: the adolescent type 1 diabetes cardio-renal intervention trial (AdDIT). Diabetes Care. (2018) 41:19639. doi: $10.2337 / \mathrm{dc} 18-1125$

48. Chiesa ST, Marcovecchio ML, Benitez-Aguirre P, Cameron FJ, Craig ME, Couper JJ, et al. Vascular effects of ACE (angiotensin-converting enzyme) inhibitors and statins in adolescents with type 1 diabetes. Hypertens. (2020) 76:1734-43. doi: 10.1161/HYPERTENSIONAHA.120. 15721

49. Di Bonito P, Mozzillo E, Esposito M, Rosanio FM, Casertano A, Fattorusso V, et al. Non-albuminuric reduced eGFR phenotype in children and adolescents with type 1 diabetes. Diabetes Res Clin Pract. (2019) 155:107781. doi: 10.1016/j.diabres.2019.07.005

50. Donaghue KC, Marcovecchio ML, Wadwa RP, Chew EY, Wong TY, Calliari LE, et al. ISPAD clinical practice consensus guidelines 2018: microvascular and macrovascular complications in children and adolescents. Pediatr Diabetes. (2018) 19:262-74. doi: 10.1111/pedi.12742

51. Zaharieva DP, Addala A, Simmons KM, Maahs DM. Weight management in youth with type 1 diabetes and obesity: challenges and possible solutions. Curr Obes Rep. (2020) 9:412-3. doi: 10.1007/s13679-020-00411-z

52. Cameron FJ, Garvey K, Hood KK, Acerini CL, Codner E. ISPAD clinical practice consensus guidelines 2018: diabetes in adolescence. Pediatr Diabetes. (2018) 19:250-61. doi: 10.1111/pedi.12702

53. Liu K, Daviglus ML, Loria CM, Colangelo LA, Spring B, Moller AC, et al. Healthy lifestyle through young adulthood and the presence of low cardiovascular disease risk profile in middle age: the coronary artery risk development in (young) adults (CARDIA) study. Circulation. (2012) 125:9961004. doi: 10.1161/CIRCULATIONAHA.111.060681

54. Devaraj SM, Kriska AM, Orchard TJ, Miller RG, Costacou T. Cardiovascular health in early adulthood predicts the development of coronary heart disease in individuals with type 1 diabetes: 25 year follow-up from the Pittsburgh epidemiology of diabetes complications study. Diabetologia. (2021) 64:57180. doi: 10.1007/s00125-020-05328-9

55. Lyons SK, Boyle CT, DeSalvo DJ, Rickels MR, Wood Heickman LK, Miller $\mathrm{KM}$, et al. Dyslipidaemia and statin use in individuals aged 10 to 40 years in the T1D exchange clinic registry. Diabetes, Obes Metab. (2019) 21:1702. doi: 10.1111/dom.13475

56. Abed E, LaBarbera B, Dvorak J, Zhang Y, Beck J, Talsania M. Prevalence of dyslipidemia and factors affecting dyslipidemia in young adults with type 1 diabetes: evaluation of statin prescribing. J Pediatr Endocrinol Metab. (2019) 32:327-34. doi: 10.1515/jpem-2018-0383

57. Shah VN, Grimsmann JM, Foster NC, Dost A, Miller KM, Pavel M, et al. Undertreatment of cardiovascular risk factors in the type 1 diabetes exchange clinic network (United States) and the prospective diabetes followup (Germany/Austria) registries. Diabetes, Obes Metab. (2020) 22:157785. doi: 10.1111/dom.14069

58. Katz ML, Guo Z, Laffel LM. Management of hypertension and high lowdensity lipoprotein in pediatric type 1 diabetes. J Pediatr. (2018) 197:1406.e12. doi: 10.1016/j.jpeds.2017.11.059

59. Marcovecchio ML, Chiesa ST, Bond S, Daneman D, Dawson S, Donaghue $\mathrm{KC}$, et al. ACE inhibitors and statins in adolescents with type 1 diabetes. N Engl J Med. (2017) 377:1733-45. doi: 10.1056/NEJMoa17 03518

60. Niechciał E, Acerini CL, Chiesa ST, Stevens T, Dalton RN, Daneman D, et al. Medication adherence during adjunct therapy with statins and ace inhibitors in adolescents with type 1 diabetes. Diabetes Care. (2020) 43:10706. doi: 10.2337/dc19-0884

61. Al Khalifah RA, Alnhdi A, Alghar H, Alanazi M, Florez ID. The effect of adding metformin to insulin therapy for type 1 diabetes mellitus children: A systematic review and meta-analysis. Pediatr Diabetes. (2017) 18:66473. doi: $10.1111 /$ pedi. 12493

62. Cree-Green M, Bergman BC, Cengiz E, Fox LA, Hannon TS, Miller $\mathrm{K}$, et al. Metformin improves peripheral insulin sensitivity in youth with type 1 diabetes. J Clin Endocrinol Metab. (2019) 104:3265-78. doi: 10.1210/jc.2019-00129

63. Anderson JJA, Couper JJ, Giles LC, Leggett CE, Gent R, Coppin B, et al. Effect of metformin on vascular function in children with type 1 diabetes: a 12-month randomized controlled trial. J Clin Endocrinol Metab. (2017) 102:4448-56. doi: 10.1210/jc.2017-00781 
64. Bjornstad P, Schäfer M, Truong U, Cree-Green M, Pyle L, Baumgartner A, et al. Metformin improves insulin sensitivity and vascular health in youth with type 1 diabetes mellitus. Circulation. (2018) 138:2895907. doi: 10.1161/CIRCULATIONAHA.118.035525

65. Snaith JR, Holmes-Walker DJ, Greenfield JR. Reducing type 1 diabetes mortality: role for adjunctive therapies? Trends Endocrinol Metab. (2020) 31:150-64. doi: 10.1016/j.tem.2019.11.007

66. Katz ML, Kaushal T, Guo Z, Cheema A, Gerrard R, Laffel LM. Adolescent and parent perceptions of long-term type 1 diabetes complications. Diabetes Spectr. (2021) 34:52-9. doi: $10.2337 / \mathrm{ds}$ 20-0042

67. Katz ML, Guo Z, Cheema A, Laffel LM. Management of cardiovascular disease risk in teens with type 1 diabetes: perspectives of teens with and without dyslipidemia and parents. Pediatr Diabetes. (2019) 20:210-6 doi: $10.1111 /$ pedi. 12771

Conflict of Interest: The authors declare that the research was conducted in the absence of any commercial or financial relationships that could be construed as a potential conflict of interest.

Copyright (C) 2021 Chiesa and Marcovecchio. This is an open-access article distributed under the terms of the Creative Commons Attribution License (CC BY). The use, distribution or reproduction in other forums is permitted, provided the original author(s) and the copyright owner(s) are credited and that the original publication in this journal is cited, in accordance with accepted academic practice. No use, distribution or reproduction is permitted which does not comply with these terms. 